\title{
COMPARAÇÃO ENTRE MÉTODOS DE DIMENSIONAMENTO DE RESERVATÓRIO PROPOSTOS PELA ABNT NBR 15527:2007 PARA SISTEMAS DE APROVEITAMENTO DE ÁGUAS PLUVIAIS EM RESIDÊNCIA UNIFAMILIAR - CARAPICUÍBA - SP
}

\author{
Comparison between methods of rainwater tank sizing suggested by ABNT NBR \\ 15527:2007 for rainwater harvesting system in a single family home - \\ CARAPICUÍBA - SP
}

Kelly Carolina Alves da SILVA ${ }^{1}$, Armando Traini FERREIRA ${ }^{2}$

Recebido em 05 de agosto de 2019; aceito em 30 de setembro de 2019; disponível on-line em 04 de junho de 2020.

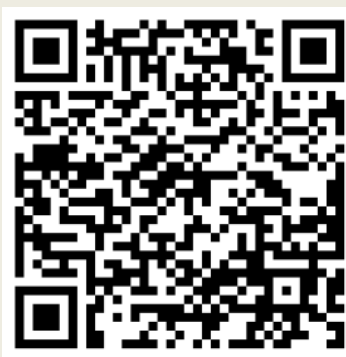

PALAVRAS CHAVE:

Sistemas de aproveitamento de água pluvial;

Dimensionamento de reservatórios;

Métodos de

dimensionamento;

Água pluvial;

NBR 15527.

\section{KEYWORDS:}

Rainwater harvesting

system;

Rainwater tank sizing;

Sizing methods;

Stormwater;

NBR 15527.

\begin{abstract}
RESUMO: As técnicas de aproveitamento de água pluvial são soluções sustentáveis que colaboram para uso racional da água, viabilizando a conservação dos recursos hídricos para as futuras gerações. O presente trabalho objetivou realizar uma comparação entre os métodos de dimensionamento de reservatórios apresentados pela ABNT NBR 15527:2007 para um sistema de aproveitamento de água pluvial em uma residência unifamiliar no município de Carapicuíba, SP. Por meio de um levantamento de usos finais de água não potável na edificação, pode-se estimar o volume de água necessário para suprir essa demanda em atividades de consumo não nobres como: lavagem de automóveis, lavagem de quintal, lavagem de calçadas e irrigação de jardins. Foi imprescindível ao estudo o levantamento de dados pluviométricos e verificação da área de captação de água pluvial do local estudado. Posteriormente à coleta dos dados citados, dimensionou-se o reservatório de água pluvial por meio de seis diferentes métodos, e fez-se uma comparação entre eles, onde foi constatado que a escolha do método ideal de dimensionamento será de acordo com os interesses finais de implantação de um sistema de aproveitamento de água pluvial e também em função da região de implantação. Sendo, no caso estudado, escolhidos como métodos que atingiram um valor mais apropriado para o reservatório aderente à demanda (volume de $3 \mathrm{~m}^{3}$ ), o método australiano e o método da simulação.
\end{abstract}

ABSTRACT: The techniques of rainwater harvesting are sustainable solutions that collaborate for the rational use of water, making conservation of water resources for future generations feasible. This paper's objective is to compare the various methods of rainwater tank sizing suggested in the Brazilian standard NBR 15527:2007 for a rainwater harvesting system in a single family home in the city of Carapicuiba, SP. By means of surveying the final uses of non-potable water in the building, it is possible to estimate the volume of water needed to supply the demand for non-potable water for activities such as car washing, backyard washing, sidewalk washing and irrigation of gardens. It was essential to the study the collection of rainfall data and verification of the rainfall catchment area of the study site. Subsequently to the data collection, the rainwater tank was sized by means of six different methods, and a comparison was made between them, where it was verified that the choice of the ideal method of sizing will be according to the final interests of implantation of a rainwater harvesting system and also according to the region of implantation. In the case studied, the methods that better adhered to the demand were the Australian method and the simulation method with a rainwater tank of volume of $3 \mathrm{~m}^{3}$.

\footnotetext{
* Contato com os autores:

${ }^{1}$ e-mail: kelly.alves108@gmail.com ( K. C. A. Silva )

Engenheira Civil, graduada pelo Instituto Federal de São Paulo - Campus São Paulo.

2e-mail: traini@ifsp.edu.br ( A. T. Ferreira )

Engenheiro Civil, Doutor, Professor, Instituto Federal de São Paulo - Campus São Paulo.
} 


\section{INTRODUÇÃO}

O uso de recursos naturais renováveis e não renováveis pelo homem trouxe com ele grandes evoluções para a civilização, mas a utilização indiscriminada de recursos tais quais as águas também trouxeram consigo limitações, já que os mesmos são finitos. No que tange aos recursos hídricos, existe uma tendência à escassez de água de boa qualidade sendo, então, necessário que se faça uso destes recursos de maneira eficiente e racional (FERREIRA et al., 2008). Desta forma, fica clara a importância de se utilizar fontes alternativas de recursos hídricos não potáveis, deixando-se de utilizar a água potável para fins menos nobres (atividades que não demandam água potável).

Há não muito tempo um problema enfrentado pela população da Região Metropolitana de São Paulo (RMSP), o maior polo de riqueza nacional segundo a EMPLASA (2017), foi a escassez de água no período de 2013 a 2014, que foi denominado de "crise hídrica". Nesse período o regime de chuvas da região sudeste do país foi atípico, apresentando uma gradativa e intensa redução nos índices pluviométricos. Fato que causou uma diminuição significativa do volume armazenado nos reservatórios dos sistemas de abastecimento público, fazendo com que alguns municípios entrassem em um racionamento de consumo d'água e em outros foi necessária até mesmo utilização de carros-pipa (ANA, 2015).

Posto isto, nota-se que é necessária a implantação de medidas capazes de reverter essa situação. Uma medida que pode ser citada é o sistema de aproveitamento de água pluvial (SPERANCETTA et al., 2004). A captação pontual de águas pluviais é uma das alternativas mais comuns para melhorar o aproveitamento dos recursos hídricos, e consiste em captar a água da chuva através de uma superfície de coleta, sendo armazenada em reservatórios para posteriormente ser distribuída. Segundo a associação Brasileira de Normas Técnicas (ABNT) através da NBR 15527 (ABNT, 2007), que define metodologias para projetos de aproveitamento de água pluvial, a água de chuva de áreas urbanas pode ser utilizada para fins não potáveis tais como limpeza externa de prédios e veículos, vasos sanitários, irrigação de jardins e reservatórios para combate de incêndios. Este artigo compreende apenas o aproveitamento das águas pluviais para fins não potáveis como, por exemplo, para a rega de jardins e a lavagem de carros, ou seja, atividades não nobres que não exigem um tratamento complexo da água.

Nesse contexto, o presente trabalho sugere a comparação entre métodos de dimensionamento de reservatório para um sistema de captação de águas pluviais que seria implantado em uma residência unifamiliar localizada em Carapicuíba, uma localidade que durante a crise hídrica de 2014 foi fortemente afetada pela falta de água, já que era abastecida pelo sistema da Cantareira - um dos mais afetados pela escassez hídrica daquele período. E assim, determinar qual método de dimensionamento de reservatório apresentado pela norma brasileira seria mais adequado a aplicação no local estudado.

\section{OBJETIVO}

Comparar os métodos de dimensionamento, segundo a NBR 15527 (ABNT, 2007), de reservatório para um sistema de aproveitamento de água pluvial para uso não potável em residência unifamiliar já construída, localizada na RMSP, e verificar qual seria o mais apropriado a se aplicar no objeto de estudo.

\section{REVISÃO BIBLIOGRÁFICA}

De acordo com Sperancetta et al. (2004), o volume total da água permanece constante no planeta, e é estimado em aproximadamente 1,4 bilhão de quilômetros cúbicos. Os oceanos representam $97 \%$ do montante efetivo de água e, consequentemente, restam apenas $2,5 \%$ de água 
doce, que permanece em ciclo de chuva, neve, evaporação e gelo. Grande parte da água doce (68,7\%) permanece como gelo e neve, 30\% está na forma de águas subterrâneas e apenas uma pequena parcela $(0,26 \%)$ compreende lagos, rios e reservatórios, que representam as formas mais fáceis e acessíveis economicamente para captação.

A água, por conseguinte, é um recurso extremamente ínfimo. O suprimento de água doce de boa qualidade é fundamental para o desenvolvimento econômico, assim como para a qualidade de vida das populações humanas e para que se mantenha a biodiversidade terrestre $e$ aquática. Deste modo, os recursos hídricos superficiais e subterrâneos são recursos estratégicos para os seres vivos (TUNDISI, 2003).

Além do fato da água doce ocorrer em pequena porcentagem na Terra e ser afetada por fatores que comprometem sua usabilidade, sua distribuição geográfica é desigual (ANA, 2016). Também é importante destacar que o crescimento populacional desordenado aliado ao uso indiscriminado e não racional da água tem levado os recursos hídricos a uma deterioração acelerada e como consequência o ser humano vem buscando reduzir seu consumo e procurando por novas fontes de abastecimento (AMORIM; PEREIRA, 2008).

De acordo com Amorim e Pereira (2008) uma das formas de reduzir o problema ambiental de escassez de água para consumo seria por meio da utilização de sistemas de aproveitamento de água pluvial, já que as águas de chuva captadas por esses sistemas poderão ser usadas em diversas atividades menos nobres que não demandam a utilização de água potável como: rega de jardim, lavagem de veículos, descargas em bacias sanitários, limpeza de calçadas, entre outros. Minimizando, assim, o uso de água potável proveniente da rede de distribuição.

O sistema de captação e utilização de água pluvial é composto pelos seguintes componentes: superfície de captação (telhado), calhas e tubulações, dispositivos de descarte para autolimpeza e reservatório de acumulação de água (COHIM et al, 2008).

O reservatório é um dos componentes mais importantes e onerosos do sistema de aproveitamento de água pluvial, assim sendo o seu dimensionamento deve ser realizado minuciosamente, pois poderá tornar a implantação do sistema inviável (MAY, 2004), motivo pelo qual este trabalhou focou neste item. Os principais critérios a serem levados em consideração no dimensionamento deverão ser: custos totais de implantação, demanda de água, áreas de captação, regime pluviométrico e confiabilidade requerida para o sistema (MARINOSKI, 2007).

Com o intuito de investigar métodos para o dimensionamento de reservatório de água pluvial para fins não potáveis, este trabalho apresenta um estudo de caso, para aplicar e comparar os seis métodos de dimensionamento apresentados na NBR 15527 (ABNT, 2007) e determinar qual seria o mais adequado a se aplicar no local de estudo.

\section{METODOLOGIA}

\subsection{MUNICÍPIO DE ESTUDO}

O município de Carapicuíba, com área de $34,967 \mathrm{~km}^{2}$, é o local de estudo escolhido e está localizado entre os paralelos $23^{\circ} 30^{\prime}$ e $23^{\circ} 35^{\prime}$ de latitude sul e entre os meridianos $46^{\circ} 45^{\prime}$ e $46^{\circ} 55^{\prime}$ de longitude oeste, estando a $21 \mathrm{~km}$ da capital São Paulo e pertencendo à RMSP. As localidades que fazem divisa com esse município são: Barueri (norte), Jandira (oeste), Cotia (sul) e Osasco (leste).

Segundo o Instituto Brasileiro de Geografia e Estatística (IBGE, 2018), a população estimada total do município é de 399.584 habitantes, sendo o segundo mais populoso de sua microrregião. Na Figura 1 pode-se observar a localização geográfica do município, destacada em cor vermelha, em relação à RMSP (EMPLASA, 2017). 


01 - Arujá
02 - Barueri
03 - Biritiba Mirim
04 - Caieiras
05 - Cajamar
06 - Carapicuíba
07 - Cotia
08 - Diadema
09 - Embu
10 - Embu Guaçu
11 - Ferraz de Vasconcelos
12 - Francisco Morato
13 - Franco da Rocha
14 - Guararema
15 - Guarulhos
16 - Itapecerica da Serra
17 - Itapevi
18 - Itaquaquecetuba
19 - Jandira
20 - Juquitiba

FIGURA 1: Localização do município em relação à RMSP FONTE: EMPLASA (2017).

\subsection{OBJETO DE ESTUDO}

O objeto de estudo, uma residência unifamiliar, está localizado na Estrada do Jacarandá no 2250, no condomínio dos Ipês, na cidade de Carapicuíba, São Paulo. A residência abriga uma família de quatro pessoas. A edificação está construída em um terreno de 194,85 m², possui três pavimentos e área construída de 268 $\mathrm{m}^{2}$. A Erro! Fonte de referência não encontrada.2 apresenta a fachada da residência e a vista aérea, em destaque.

\subsection{LEVANTAMENTO DE DADOS}

\subsubsection{Dados pluviométricos}

Os dados pluviométricos coletados são provenientes de pluviômetro automático do Centro Nacional de Monitoramento e Alertas de Desastres Naturais - CEMADEN. O posto pluviométrico escolhido foi o de Altos de Santa Lúcia, que possui o código $351060901 \mathrm{~A}$, o mais próximo do local de estudo, sendo localizado inclusive no mesmo bairro. As coordenadas geográficas do posto são: latitude $23^{\circ} 33^{\prime}$ Sul e longitude $46^{\circ} 50^{\prime}$ Oeste. A presença do equipamento pluviômetro nesse ponto é relativamente nova, segundo a CEMADEN ele foi instalado em 2013. Porém, foram disponibilizados os dados a partir de agosto de 2015. A partir desses índices, foram calculadas as médias mensais de 01/08/2015 a 31/12/2018. Então, foi elaborado o gráfico apresentado na Figura $3 \mathrm{com}$ as médias pluviométricas adquiridas, tornando possível observar a sazonalidade local.
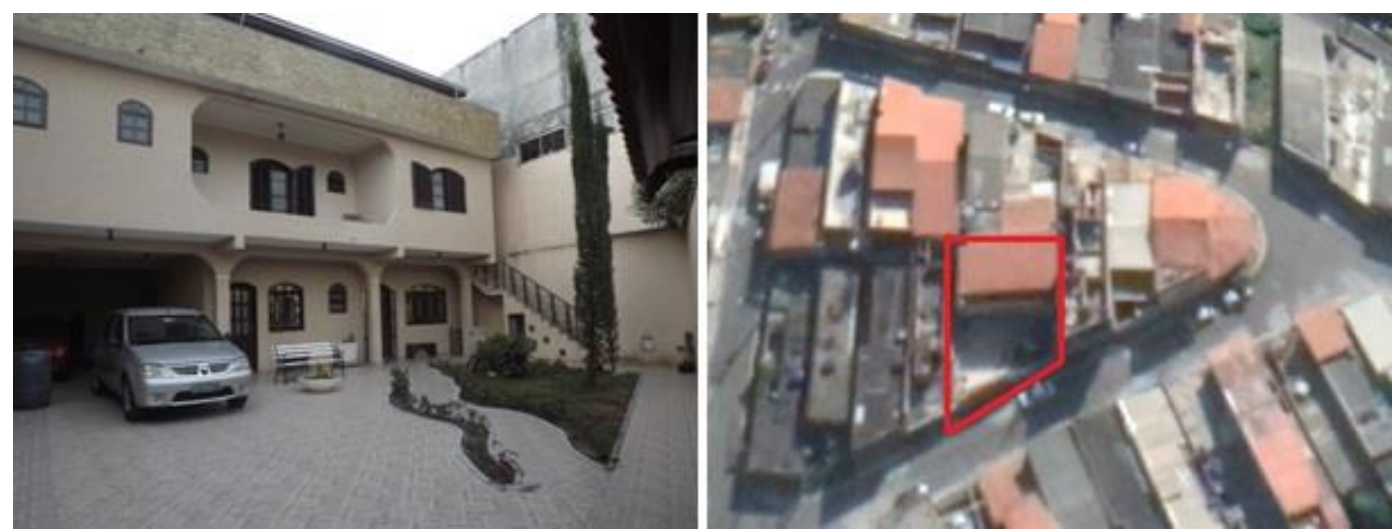

FIGURA 2: Fachada da Residência e vista aérea FONTE: Autor (2016); Google Earth (2018). 


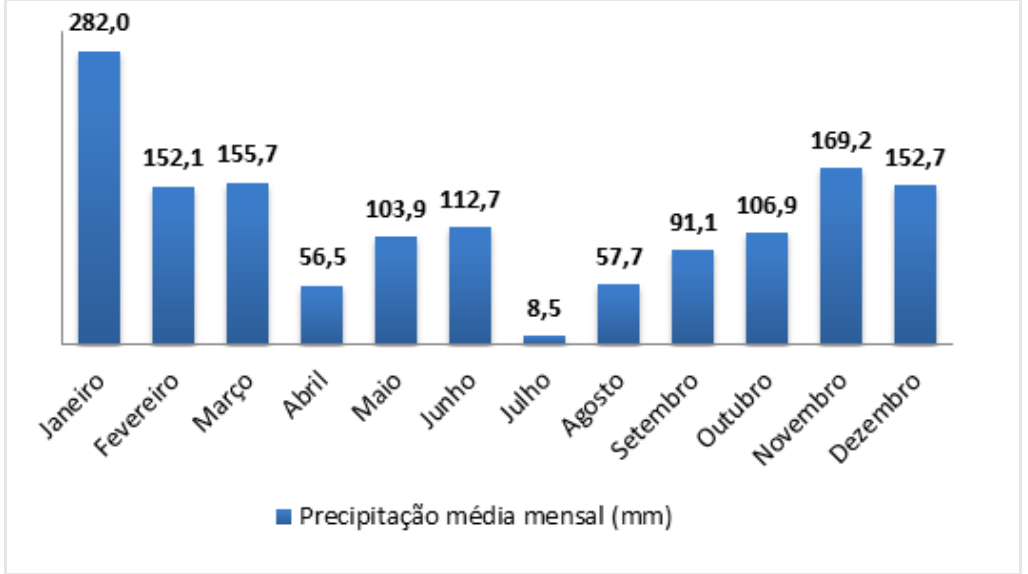

FIGURA 3: Precipitação média mensal 2015 - 2018

FONTE: Adaptado CEMADEN (2019).

\subsection{2 Área de captação}

A área de captação foi obtida a partir de medidas verificadas na planta de cobertura do imóvel, seu cálculo foi realizado por meio do software AutoCad, já que segundo a NBR 15527 (ABNT, 2007) o cálculo da área de captação é a projeção das medidas do telhado na horizontal. A área obtida foi de cerca de $87,15 \mathrm{~m}^{2}$.

\subsubsection{Demanda para uso de água não potável}

Outro dado levantado foi o consumo de água em atividades que não demandam a utilização de água potável, ou seja, aquelas que poderão usufruir da água proveniente do sistema de aproveitamento de águas pluviais. Foi levantada a quantidade de água dispendida para a limpeza de quintal/calçada, lavagem de veículos e rega de jardim e a frequência em que essas atividades são realizadas. No caso da rega de jardim, que é efetuada com mangueira, foi calculada a vazão do equipamento. Para realizar esse cálculo foi usado um recipiente de volume conhecido e cronômetro, responsável por apontar o tempo necessário para o enchimento do recipiente. Posteriormente foi cronometrado o tempo médio gasto diariamente na rega, que foi medido em sete ocasiões distintas, e através da multiplicação entre vazão e tempo gasto na atividade pode-se obter a demanda de água da mesma, como pode ser visto na Equação 1.

$$
\operatorname{Drj}=\mathrm{Qm} \times \mathrm{t} \quad \text { Eq.[1] }
$$

Em que:

$\mathbf{D}_{\mathrm{rj}}=$ demanda diária de água usada na rega de jardim (L);

$\mathbf{Q}_{\mathrm{m}}=$ vazão da mangueira ( $\left.\mathrm{L} / \mathrm{min}\right)$;

$\mathbf{t}=$ tempo médio de duração da rega de jardim (min).

Nas outras atividades, que são realizadas com baldes, foram estabelecidos como dados necessários para encontrar a demanda de água o volume do recipiente e a quantidade de recipientes utilizados na atividade. Em seguida, foi levantada a frequência em que essas atividades ocorriam. Dessa maneira, foram obtidas as demandas semanal e mensal de água para uso não potável. O cálculo está representado na Equação 2.

$$
D_{1}=V_{r} \times q \times f
$$

\section{Em que:}

D 1 = demanda semanal de água para as atividades de limpeza de calçada, quintal e lavagem de veículos (L);

$\mathbf{V}_{\mathrm{r}}=$ volume do recipiente utilizado $(\mathrm{L})$;

$\mathbf{q}=$ quantidade de recipientes usados no desenvolvimento da atividade;

$f$ = frequência com que a atividade ocorre (vezes/semana).

Por fim, foi realizado o cálculo da demanda mensal por água não potável. Expresso, a seguir, na Equação 3. 


$$
\mathrm{D}=\mathrm{D}_{\mathrm{rj}}+\mathrm{D}_{\mathrm{l}}
$$

Em que:

D = demanda mensal da água não potável (L);

D $_{\mathrm{rj}}=$ Demanda mensal usada na irrigação de jardim (L);

$\mathbf{D}_{\mathbf{1}}=$ demanda mensal de água para as atividades de limpeza de calçada, quintal e lavagem de veículos (L).

\subsubsection{Coeficiente de runoff}

Segundo Tomaz (2010), o coeficiente de runoff para telhas de material cerâmico é 0,8 , para aquelas de cimento amianto está entre 0,8 a 0,9, já para as telhas de metal está entre 0,7 a 0,9 e para as de plástico encontra-se entre 0,9 e 0,95. Para os cálculos realizados neste estudo o coeficiente de runoff adotado foi de 0,8 , posto que o telhado do objeto de estudo é composto por telhas de material cerâmico.

\subsection{DIMENSIONAMENTO DO RESERVATÓRIO DE ÁGUA PLUVIAL}

O reservatório está ligado à confiabilidade do sistema, desempenhando um papel primordial em evitar ocorrências em que a quantidade de água é insuficiente para atender à demanda. As principais variáveis a serem levadas em consideração no dimensionamento devem ser: demanda de água, áreas de captação e regime pluviométrico (MARINOSKI, 2007).

Não há apenas um método de se calcular o dimensionamento de um reservatório de água pluvial, ou seja, não existe ainda um método ideal/único. Neste estudo, foram abordados os apresentados na NBR 15527 (ABNT, 2007), e a partir de comparação e análise dos resultados foi escolhido o método que melhor se encaixa no caso estudado e este foi então considerado como o volume ideal. A seguir serão apresentados os métodos de cálculo.

\subsubsection{Método de Rippl}

Segundo Tomaz (2010), no método de Rippl podem ser empregadas as séries históricas mensais, do período de tempo mais extenso possível, ou diárias de precipitação. Caso opte-se por fazer o dimensionamento usando a série diária de precipitação, utiliza-se uma série histórica de no mínimo 10 anos de precipitações diárias, caso este dado não esteja disponível deverá ser empregada a série mensal. No desenvolvimento desta pesquisa são utilizados os totais mensais das séries históricas. Para o dimensionamento as Equações 4, 5 e 6 a seguir devem ser aplicadas:

$$
\begin{array}{ll}
\mathrm{St}=\mathrm{Dt}-\mathrm{Qt} & \text { Eq.[4] } \\
\mathrm{Qt}=\mathrm{C} \times \mathrm{P} \times \mathrm{A} & \text { Eq.[5] }
\end{array}
$$

$\mathrm{V}=\sum \mathrm{St}$, somentepara valoresSt maior que zero Eq.[6] Em que:

$\mathbf{S}_{\mathrm{t}}=$ volume de água pluvial no reservatório no tempo t (L);

$\mathbf{D}_{\mathrm{t}}=$ demanda ou consumo de água pluvial no tempo t (L);

$\mathbf{Q}_{\mathbf{t}}=$ volume de água pluvial no tempo $\mathbf{t}(\mathrm{L})$;

$\mathbf{C}=$ coeficiente de runoff/escoamento superficial (adimensional);

$\mathbf{P}=$ precipitação média no tempo $t(\mathrm{~mm})$;

$\mathbf{A}=$ área de captação em projeção no terreno $\left(\mathrm{m}^{2}\right)$;

$\mathbf{V}=$ volume do reservatório $(\mathrm{L})$.

\subsubsection{Método da Simulação}

Para este método são estabelecidas pela NBR 15527 (ABNT, 2007) duas pressuposições:

(a) o reservatório está cheio no início da contagem do tempo t;

(b) os dados históricos são representativos para as condições futuras.

A norma também recomenda que, nesse método, a evaporação da água não seja levada em conta. O método da Simulação toma como base a determinação do percentual de consumo que será atendido em função de um tamanho de reservatório previamente definido. De acordo com Tomaz (2010), uma característica deste método é que ele permite determinar a eficiência do sistema, pois os períodos em que o reservatório está suficientemente abastecido com água pluvial são relacionados com todo o período simulado. Tal período pode ser de apenas um ano mas, quanto maior a série histórica de precipitação utilizada, maior será a confiabilidade da simulação. Assim 
sendo, neste método de cálculo é deduzido um volume para o reservatório e então é feita uma verificação do que ocorre, ou seja, é um método de tentativa e erro. O dimensionamento do reservatório de água pluvial pelo método da Simulação tem início pelo cálculo do volume de água pluvial no tempo $\mathrm{t}$ e do volume de água pluvial no reservatório no tempo $t$, através das Equações 5 e 7 respectivamente.

$$
\mathrm{S}_{\mathrm{t}}=\mathrm{Q}_{\mathrm{t}}+\mathrm{S}_{\mathrm{t}-1-\mathrm{Dt}}
$$

Em que:

$\mathbf{S}_{\mathbf{t}}=$ volume de água pluvial no reservatório no tempo $\mathrm{t}(\mathrm{L})$;

$\mathbf{Q}_{\mathbf{t}}=$ volume de água pluvial no tempo $\mathrm{t}(\mathrm{L})$;

$\mathbf{S}_{\mathrm{t}-1}=$ volume de água pluvial no reservatório no tempo t-1 (L);

$\mathbf{D}_{\mathbf{t}}=$ demanda ou consumo de água pluvial no tempo $\mathrm{t}(\mathrm{L})$.

Define-se, posteriormente, um volume de reservatório $\mathrm{V}$ (volume do reservatório fixado) que atenda, para o mês de janeiro, à condição $V \geq$ $\mathrm{S}(\mathrm{t}) \geq 0$. Se essa condição for atendida ao longo dos demais 11 meses do ano, esse volume $V$ é o volume a ser adotado no reservatório. Se a condição não for atendida, deve-se determinar outro volume de reservatório $V$ até que se atenda à condição $\mathrm{V} \geq \mathrm{S}(\mathrm{t}) \geq 0$ para os 12 meses do ano.

\subsubsection{Método Azevedo Neto}

Segundo Cohim et al. (2008), este método também é conhecido como Método Prático Brasileiro e é o primeiro método empírico apresentado pela NBR 15527 (ABNT,2007). Neste método, diferente dos que foram apresentados até o momento, é desconsiderada a influência da demanda, levando-se em conta apenas a precipitação média anual, a área de captação e o período de estiagem (mensal). O volume do reservatório é calculado mediante a Equação 8. O coeficiente 0,042 existe para assegurar que o tempo máximo de retenção da água na cisterna seja de, aproximadamente, 15 dias durante um ano (ANQUIP, 2009).

$$
\mathrm{V}=0,042 \times \mathrm{P} \times \mathrm{A} \times \mathrm{T}
$$

Em que:

V = volume de água no reservatório, ou o volume do reservatório de água pluvial (L);

$\mathbf{P}=$ precipitação média anual $(\mathrm{mm})$;

$\mathbf{A}=$ área de captação em projeção no terreno $\left(\mathrm{m}^{2}\right)$;

$\mathbf{T}=$ número de meses de pouca chuva ou seca.

Não é especificado na NBR 15527 (ABNT, 2007) como determinar o número de meses de pouca chuva. Desta forma, foi adotado para o cálculo de $T$ que os meses com precipitação igual ou inferior a $70 \%$ da média mensal seriam considerados como meses de pouca chuva. $\mathrm{Na}$ Tabela 1 pode-se observar os valores das precipitações média anual e mensal, assim como o valor desta última multiplicado por $70 \%$ e a quantidade de meses de pouca chuva adotados para 0 dimensionamento.

\begin{tabular}{cc}
\hline \multicolumn{2}{c}{ TABELA 1: Meses de pouca chuva } \\
\hline $\begin{array}{c}\text { Precipitação média } \\
\text { anual (mm) }\end{array}$ & 1449 \\
\hline $\begin{array}{c}\text { Precipitação média } \\
\text { mensal (mm) }\end{array}$ & 121 \\
\hline $\begin{array}{c}\text { 70\% da Precipitação } \\
\text { média mensal (mm) }\end{array}$ & 85 \\
\hline T (meses) & 3 \\
\hline FONTE: Adaptado CEMADEN (2019).
\end{tabular}

\subsubsection{Método Prático Alemão}

Este método, também empírico, segundo a NBR 15527 (ABNT, 2007) considera que o tamanho do reservatório será $6 \%$ da demanda anual por água pluvial ou do volume anual de precipitação captada, adotando aquele que for menor. O cálculo deste método está expresso na Equação 9, apresentada abaixo.

$$
\mathrm{V}_{\text {adotado }}=\operatorname{mín}(\mathrm{V} ; \mathrm{D}) \times 0,06
$$

Em que:

$\mathbf{V}_{\text {adotado }}=$ volume do reservatório $(\mathrm{L})$;

$\mathbf{V}=$ volume de água pluvial anual (L);

D = demanda anual da água não potável (L). 
Na NBR 15527 (ABNT, 2007) não está explicito como se obtém o volume de água pluvial anual pelo método Prático Alemão. Sendo assim, esse valor foi obtido com o uso da Equação 5. A demanda anual de água não potável, por sua vez, foi obtida por meio da multiplicação da demanda mensal (Equação 3) por 12 meses.

\subsubsection{Método Prático Inglês}

Este método é similar ao de Azevedo Neto, segundo a NBR 15527 (ABNT, 2007) para o cálculo do volume do reservatório de água pluvial deve-se utilizar a Equação 10.

$$
\mathrm{V}=0,05 \times \mathrm{P} \times \mathrm{A}
$$

Em que:

$\mathbf{V}$ = volume de água aproveitável e o volume do reservatório de água pluvial (L);

$\mathbf{P}=$ precipitação média anual $(\mathrm{mm})$;

$\mathbf{A}=$ área de captação em projeção no terreno $\left(\mathrm{m}^{2}\right)$.

\subsubsection{Método Prático Australiano}

Este é o último método sugerido pela NBR 15527 (ABNT, 2007), o primeiro passo no dimensionamento segundo o método prático australiano é o cálculo do volume de chuva, apresentado na Equação 11. Em seguida, é efetuado o cálculo do volume do reservatório através de tentativas, considerando o reservatório vazio no primeiro mês, até que seja alcançado um valor dentro de um intervalo de confiança de $90 \%$ a $99 \%$. O cálculo do volume pode ser visto abaixo na Equação 12. Sendo que quando $V(t-1)+Q(t)-$ $D(t))<0$, então $\circ V(t)=0$. $O$ cálculo da confiança é realizado por meio das Equações 13 e 14.

$$
\begin{gathered}
\mathrm{Q}=\mathrm{A} \times \mathrm{C} \times(\mathrm{P}-\mathrm{I}) \\
\mathrm{V}_{\mathrm{t}}=\mathrm{V}_{\mathrm{t}-1}+\mathrm{Q}_{\mathrm{t}}-\mathrm{D}_{\mathrm{t}} \\
\mathrm{P}_{\mathrm{r}}=\frac{\mathrm{N}_{\mathrm{r}}}{\mathrm{N}}
\end{gathered}
$$

$$
\text { Confiança }=\left(1-P_{r}\right)
$$

Em que:

$\mathbf{Q}=$ volume mensal de água pluvial ( $\mathrm{L})$;

$\mathbf{A}=$ área de captação em projeção no terreno $\left(\mathrm{m}^{2}\right)$;

$\mathbf{C}=$ coeficiente de runoff/escoamento superficial (adimensional);

$\mathbf{P}=$ precipitação média mensal $(\mathrm{mm})$;

I = interceptação da água que molha as superfícies e as perdas por evaporação (de acordo com a NBR 15527 (ABNT, 2007), geralmente adota-se como $2 \mathrm{~mm}$ );

$\mathbf{V}_{\mathbf{t}}=$ volume de água pluvial que está no reservatório no fim do mês $\mathrm{t}(\mathrm{L})$;

$\mathbf{V}_{\mathrm{t}-1}=$ volume de água pluvial que está no reservatório no início do mês $\mathrm{t}(\mathrm{L})$;

$\mathbf{Q}_{\mathrm{t}}=$ volume de água pluvial no mês $\mathrm{t}(\mathrm{L})$;

$\mathbf{D}_{\mathrm{t}}=$ demanda mensal de água não potável $(\mathrm{L})$;

$\mathbf{P}_{\mathbf{r}}=$ falha do sistema;

$\mathbf{N}_{\mathbf{r}}=$ número de meses em que o reservatório não atendeu à demanda (quando $V_{t}=0$ );

$\mathbf{N}=$ número de meses considerados (geralmente 12 meses).

\section{RESULTADOS E DISCUSSÃO}

\subsection{DEMANDA PARA USO DE ÁGUA NÃO POTÁVEL}

Outra etapa do estudo foi calcular o consumo de água em atividades que não demandam a utilização de água potável, ou seja, aquelas que poderão usufruir da água proveniente do sistema de aproveitamento de águas pluviais. Foi verificada a quantidade de água dispendida para a limpeza de pisos de quintal e calçada, lavagem de veículos e rega de jardim, e a frequência em que essas atividades são realizadas baseado em informações fornecidas pelos moradores da residência. Esses dados coletados são necessários para estimar a demanda para o uso de água pluvial, valor que será usado no dimensionamento do reservatório do sistema de aproveitamento de água pluvial.

Através das equações apresentadas no item 4.3.3 foram obtidas as demandas mensais de água para uso não potável. Os valores de demandas mensais obtidos até esse ponto foram então somados e foi encontrado o valor total da demanda de água para uso não potável da residência, apresentado na Tabela 2 . 


\section{TABELA 2: Demanda mensal total}

\begin{tabular}{ccc} 
Atividade & Consumo (L) & Consumo $\left(\mathbf{m}^{\mathbf{3}}\right)$ \\
\hline Rega de jardim & 412,52 & 0,41 \\
\hline Lavagem de veículos & 768,00 & 0,77 \\
\hline $\begin{array}{c}\text { Lavagem de } \\
\text { calçada/quintal }\end{array}$ & 1344,00 & 1,34 \\
\hline Total & 2524,52 & 2,52 \\
\hline
\end{tabular}

FONTE: Autoria própria (2019)

\subsection{DIMENSIONAMENTO DO RESERVATÓRIO DE ÁGUA PLUVIAL}

Nesta seção apresentam-se os resultados dos dimensionamentos dos reservatórios de água pluvial calculados pelos diferentes métodos apresentados na NBR 15527 (ABNT, 2007) aplicados ao caso estudado, bem como efetua-se uma comparação entre os resultados obtidos através da utilização dos mesmos.

\subsubsection{Método de Rippl}

O volume do reservatório, segundo dimensionamento efetuado pelo Método de Rippl, foi realizado aplicando as variáveis, que no caso são precipitação média mensal, coeficiente de escoamento superficial, área de captação e demanda mensal para uso de água pluvial, nas equações presentes no item 4.4.1.

Foram utilizados os dados de precipitação média mensal dos anos de 2015 a 2018, fornecidos pela CEMADEN. O coeficiente de escoamento superficial adotado foi de 0,80, para telhas de material cerâmico, indicando que $20 \%$ da água de chuva captada corresponde a perdas devido limpeza de telhado, evaporação e descarte (May, 2004). Por meio da análise da planta de cobertura da residência, verificou-se que a área captação do telhado é de cerca de $87,15 \mathrm{~m}^{2}$. A demanda mensal para uso de água pluvial calculado foi de 2524,52 litros/mês, ou seja, $2,52 \mathrm{~m}^{3} / \mathrm{mês}$.

TABELA 3: Dimensionamento utilizando o Método de Rippl.

\begin{tabular}{lccccc} 
Meses & $\begin{array}{c}\text { Chuva média } \\
\text { mensal }\end{array}$ & $\begin{array}{c}\text { Demanda } \\
\text { mensal }\end{array}$ & $\begin{array}{c}\text { Área de } \\
\text { captação }\end{array}$ & $\begin{array}{c}\text { Volume de } \\
\text { chuva mensal }\end{array}$ & $\begin{array}{c}\text { Diferença entre o } \\
\text { volume da demanda e } \\
\text { volume de chuva }\end{array}$ \\
\hline Janeiro & $\mathbf{P} \mathbf{m})$ & $\mathbf{D}_{(\mathbf{t})}\left(\mathbf{m}^{\mathbf{3}}\right)$ & $\mathbf{A}\left(\mathbf{m}^{\mathbf{2}}\right)$ & $\mathbf{Q}_{(\mathbf{t})}\left(\mathbf{m}^{\mathbf{3}}\right)$ & $\mathbf{S}_{(\mathbf{t})}\left(\mathbf{m}^{\mathbf{3}}\right)$ \\
\hline Fevereiro & 152,1 & 2,52 & 87,15 & 20 & $-17,48$ \\
\hline Março & 155,7 & 2,52 & 87,15 & 11 & $-8,48$ \\
\hline Abril & 56,5 & 2,52 & 87,15 & 11 & $-8,48$ \\
\hline Maio & 103,9 & 2,52 & 87,15 & 4 & $-1,48$ \\
\hline Junho & 112,7 & 2,52 & 87,15 & 7 & $-4,48$ \\
\hline Julho & 8,5 & 2,52 & 87,15 & 1 & $-5,48$ \\
\hline Agosto & 57,7 & 2,52 & 87,15 & 4 & 1,52 \\
\hline Setembro & 91,1 & 2,52 & 87,15 & 6 & $-1,48$ \\
\hline Outubro & 106,9 & 2,52 & 87,15 & 7 & $-3,48$ \\
\hline Novembro & 169,2 & 2,52 & 87,15 & 12 & $-4,48$ \\
\hline Dezembro & 152,7 & 2,52 & 87,15 & 11 & $-9,48$ \\
\hline Total & 1449 & 30,24 & & 102 & $-8,48$ \\
\hline & & & & & Volume=1,52 \\
\hline
\end{tabular}


A TABELA 3 apresenta os resultados dos cálculos efetuados e é possível observar que a condição para a utilização desse método, que é o somatório das demandas no tempo $\mathrm{t}$ deve ser menor do que o somatório do volume de água de chuva aproveitável no tempo $\mathrm{t}(\Sigma \mathrm{D}(\mathrm{t})<\Sigma \mathrm{Q}(\mathrm{t}))$, é atendida. Visto que $\Sigma \mathrm{D}(\mathrm{t})=30,24 \mathrm{~m}^{3}<\Sigma \mathrm{Q}(\mathrm{t})=$ $102 \mathrm{~m}^{3}$. Por fim, o volume do reservatório utilizando esse método foi de $1,52 \mathrm{~m}^{3}$.

\subsubsection{Método da Simulação}

No método da simulação foram utilizados os dados referentes à precipitação média mensal, demanda de água mensal e área de captação. Esse método trabalha com hipóteses de volumes de reservatórios, ou seja, tem-se que adotar um volume, realizando tentativas. Foi considerado um volume de $3 \mathrm{~m}^{3}$ para este, aplicando-se as Equações 5 e 7, conforme mostra a Tabela 4. Como o suprimento de água externo zerou em todos os meses utilizando um reservatório de $3 \mathrm{~m}^{3}$, esse foi o volume de água considerado para esse reservatório.

\section{TABELA 4: Dimensionamento do reservatório utilizando o Método da simulação.}

\begin{tabular}{|c|c|c|c|c|c|c|c|}
\hline Meses & $\begin{array}{l}\text { Chuva } \\
\text { média } \\
\text { mensal } \\
\text { (mm) }\end{array}$ & $\begin{array}{c}\text { Demanda } \\
\text { mensal } \\
\left(\mathrm{m}^{3}\right)\end{array}$ & $\begin{array}{c}\text { Área de } \\
\text { captação } \\
\left(\mathrm{m}^{2}\right)\end{array}$ & $\begin{array}{c}\text { Volume de } \\
\text { chuva } \\
\text { mensal } \\
\left(\mathrm{m}^{3}\right)\end{array}$ & $\begin{array}{l}\text { Volume do } \\
\text { reservatório } \\
\text { fixado } \\
\left(\mathrm{m}^{3}\right)\end{array}$ & $\begin{array}{l}\text { Volume do } \\
\text { reservatório no } \\
\text { tempo }(\mathrm{t}-1) \\
\left(\mathrm{m}^{3}\right)\end{array}$ & $\begin{array}{c}\text { Volume do } \\
\text { reservatório } \\
\text { no tempo (t) } \\
\left(\mathrm{m}^{3}\right)\end{array}$ \\
\hline Janeiro & 282 & 2,52 & 87,15 & 20 & 3 & 0 & 3 \\
\hline Fevereiro & 152,1 & 2,52 & 87,15 & 11 & 3 & 3 & 3 \\
\hline Março & 155,7 & 2,52 & 87,15 & 11 & 3 & 3 & 3 \\
\hline Abril & 56,5 & 2,52 & 87,15 & 4 & 3 & 3 & 3 \\
\hline Maio & 103,9 & 2,52 & 87,15 & 7 & 3 & 3 & 3 \\
\hline Junho & 112,7 & 2,52 & 87,15 & 8 & 3 & 3 & 3 \\
\hline Julho & 8,5 & 2,52 & 87,15 & 1 & 3 & 3 & 1,48 \\
\hline Agosto & 57,7 & 2,52 & 87,15 & 4 & 3 & 1,48 & 2,96 \\
\hline Setembro & 91,1 & 2,52 & 87,15 & 6 & 3 & 2,96 & 3 \\
\hline Outubro & 106,9 & 2,52 & 87,15 & 7 & 3 & 3 & 3 \\
\hline Novembro & 169,2 & 2,52 & 87,15 & 12 & 3 & 3 & 3 \\
\hline Dezembro & 152,7 & 2,52 & 87,15 & 11 & 3 & 3 & 3 \\
\hline Total & 1449 & 30,24 & & 102 & & & \\
\hline
\end{tabular}




\subsubsection{Método Azevedo Neto}

Nesse método foi considerada a precipitação média anual de 1448,90 mm (2015 2018). Para se obter o número de meses de pouca chuva considerou-se os meses com precipitação menor que $85 \mathrm{~mm}$, ou seja, os que não alcançam $70 \%$ da precipitação média mensal. Em seguida, aplicando a Equação 8, obteve-se um reservatório de 15,91 $\mathrm{m}^{3}$, como mostra a Tabela 5 .

\begin{tabular}{cc}
\hline \multicolumn{2}{|c}{ TABELA 5: Dimensionamento do reservatório } \\
utilizando o Método Azevedo Neto
\end{tabular}

FONTE: Adaptado ABNT (2007).

\subsubsection{Método Prático Alemão}

Para este método foram consideradas precipitação anual média de $1448,90 \mathrm{~mm}$ e demanda anual média da água não potável de $30,24 \mathrm{~m}^{3}$ (30240 L). Foi considerado que o tamanho do reservatório será $6 \%$ da demanda anual por água pluvial ou do volume anual de precipitação captada, adotando aquele que for menor (Tabela 6). Aplicando a Equação 9, obtevese um volume de $1,81 \mathrm{~m}^{3}(1814,40 \mathrm{~L})$ para o reservatório calculado.

TABELA 6: Dimensionamento segundo o Método Prático Alemão utilizando a demanda média anual de água não potável

Demanda anual de água não potável

Volume aproveitável
(L)

(L)

$30240 \quad 1814,40$

FONTE: Adaptado ABNT (2007).
Porém, como a demanda por água pluvial é de $2,52 \mathrm{~m}^{3} / \mathrm{mês}$ o volume calculado por esse método seria insuficiente para supri-la.

\subsubsection{Método Prático Inglês}

Para esse método foram consideradas a precipitação média anual igual a 1448,90 $\mathrm{mm}$ e a área de captação de $87,15 \mathrm{~m}^{2}$. Aplicando a Equação 10 obteve-se um reservatório de $6,31 \mathrm{~m}^{3}$, conforme a Tabela 7.

\section{TABELA 7: Dimensionamento utilizando o Método Prático Inglês

Precipitação média anual
(mm)

Área de captação

$\left(m^{2}\right)$

87,15

\begin{tabular}{cc}
$\begin{array}{c}\text { Volume do Reservatório } \\
(\mathrm{L})\end{array}$ & 6313,58 \\
\hline $\begin{array}{c}\text { Volume do Reservatório } \\
\left(\mathrm{m}^{3}\right)\end{array}$ \\
\hline
\end{tabular}

\subsubsection{Método Prático Australiano}

Para realizar o cálculo do volume do reservatório pelo método australiano é necessário que se faça tentativas, considerando 0 reservatório vazio no primeiro mês, até que seja alcançado um valor dentro de um intervalo de confiança de $90 \%$ a $99 \%$. O cálculo do volume é baseado na Equação 12 e resultou em um reservatório de volume igual a $3 \mathrm{~m}^{3}$, como é mostrado na Tabela 8.

Na Tabela 9, é possível observar as outras tentativas que foram realizadas. $O$ volume de $3 \mathrm{~m}^{3}$ foi escolhido, pois atende à condição de possuir mais de $90 \%$ de confiança e, também, atende à demanda mensal por água pluvial. 
Tabela 8: Dimensionamento utilizando o Método Prático Australiano.

\begin{tabular}{|c|c|c|c|c|c|}
\hline Meses & $\begin{array}{l}\text { Precipitação } \\
\text { média mensal }\end{array}$ & $\begin{array}{c}\text { Volume de } \\
\text { água pluvial no } \\
\text { mês t }\end{array}$ & $\begin{array}{c}\text { Demanda } \\
\text { mensal }\end{array}$ & $\begin{array}{l}\text { Volume de água } \\
\text { pluvial no } \\
\text { reservatório no } \\
\text { início do mês t-1 }\end{array}$ & $\begin{array}{c}\text { Volume de água pluvial no } \\
\text { reservatório no fim do mês } \\
\text { t }\end{array}$ \\
\hline & $(\mathrm{mm})$ & $\left(\mathrm{m}^{3}\right)$ & $\left(\mathrm{m}^{3}\right)$ & $\left(m^{3}\right)$ & $\left(m^{3}\right)$ \\
\hline Janeiro & 282 & 19,52 & 2,52 & 0 & 3,00 \\
\hline Fevereiro & 152,1 & 10,46 & 2,52 & 3,00 & 3,00 \\
\hline Março & 155,7 & 10,72 & 2,52 & 3,00 & 3,00 \\
\hline Abril & 56,5 & 3,80 & 2,52 & 3,00 & 3,00 \\
\hline Maio & 103,9 & 7,10 & 2,52 & 3,00 & 3,00 \\
\hline Junho & 112,7 & 7,72 & 2,52 & 3,00 & 3,00 \\
\hline Julho & 8,5 & 0,45 & 2,52 & 3,00 & 0,93 \\
\hline Agosto & 57,7 & 3,88 & 2,52 & 0,93 & 2,30 \\
\hline Setembro & 91,1 & 6,21 & 2,52 & 2,30 & 3,00 \\
\hline Outubro & 106,9 & 7,31 & 2,52 & 3,00 & 3,00 \\
\hline Novembro & 169,2 & 11,66 & 2,52 & 3,00 & 3,00 \\
\hline Dezembro & 152,7 & 10,51 & 2,52 & 3,00 & 3,00 \\
\hline
\end{tabular}

\begin{tabular}{cc}
\multicolumn{2}{|c|}{ Tabela 9: Demais volumes testados. } \\
\hline Volume do reservatório $\left(\mathbf{m}^{\mathbf{3}}\right)$ & $\begin{array}{c}\text { Confiança do } \\
\text { sistema (\%) }\end{array}$ \\
\hline 1,00 & 83,00 \\
\hline 3,00 & 91,00 \\
\hline 5,00 & 100,00 \\
\hline & FONTE: Adaptado ABNT (2007).
\end{tabular}

\subsection{ANÁLISE COMPARATIVA ENTRE OS MÉTODOS DE DIMENSIONAMENTO PROPOSTOS PELA NBR 15527}

A Tabela 10 apresenta os volumes obtidos para o dimensionamento do reservatório de água pluvial.

Como pode ser analisado, foram encontradas divergências entre as diferentes metodologias propostas pela NBR 15527 (ABNT, 2007) para o dimensionamento de reservatórios.

Apesar disso, dentre os seis métodos propostos pela NBR 15527 (ABNT, 2007) aplicados ao objeto de estudo do presente trabalho não houve grande amplitude entre os resultados encontrados, visto que 4 dos 6 métodos utilizados chegaram em volumes de valores relativamente próximos. Sendo eles: Método de Rippl, com volume obtido de $1,52 \mathrm{~m}^{3}$, Método prático alemão, com volume obtido de $1,81 \mathrm{~m}^{3}$ e Métodos da simulação e prático australiano, ambos com volume obtido igual a $3 \mathrm{~m}^{3}$. Como os reservatórios são construídos com valores fechados de volume, os volumes obtidos foram arredondados para valores inteiros (volume considerado).

Nos outros dois métodos de cálculo, sendo eles: Método prático inglês (volume do reservatório encontrado: 6,31 $\mathrm{m}^{3}$ ) e o Método Azevedo Neto (volume do reservatório encontrado: $15,91 \mathrm{~m}^{3}$ ), a variação foi consideravelmente maior em relação aos outros quatro métodos, sendo considerado para o Método prático inglês um volume de $7 \mathrm{~m}^{3}$ e para o método Azevedo Neto um volume de $16 \mathrm{~m}^{3}$. 
Tabela 10: Dimensionamento do reservatório

\begin{tabular}{lcc} 
Métodos & $\begin{array}{c}\text { Reservatório } \\
\text { (volume obtido) }\end{array}$ & $\begin{array}{c}\text { Reservatório } \\
\text { (volume } \\
\text { considerado) } \\
\left(\mathbf{m}^{\mathbf{3}}\right)\end{array}$ \\
\hline Método de Rippl & 1,52 & 2,00 \\
\hline Método da Simulação & 3,00 & 3,00 \\
\hline Método Azevedo Neto & 15,91 & 16,00 \\
\hline Método Prático Alemão & 1,81 & 2,00 \\
\hline Método Prático Inglês & 6,31 & 7,00 \\
\hline Método Prático Australiano & 3,00 & 3,00 \\
\hline & & FONTE: Adaptado ABNT (2007).
\end{tabular}

Comparando os resultados encontrados é possível observar que o método Azevedo Neto obtém um volume muito maior que os outros métodos, superdimensionando o volume do mesmo, o que teria um impacto econômico na implantação de um reservatório, ou seja, tornaria sua aplicação mais onerosa podendo inviabilizar a implantação do sistema. Outro método que superdimensiona o volume do reservatório é o prático inglês. Esses dois métodos de cálculo levam em consideração a precipitação anual e área de captação, mas não a demanda, o que pode ter colaborado para o superdimensionamento. Reservatórios dimensionados por esses métodos podem ser aplicados em locais em que se almeja suprir a demanda de água pluvial por todo o ano ou para a maior parte do ano possível, como, por exemplo, em regiões onde ocorre carência de água sazonalmente.

Os métodos de Rippl e o prático alemão encontraram valores próximos (com variação entre si de $0,29 \mathrm{~m}^{3}$ ) e menores, demonstrando que há um subdimensionamento do sistema, ou seja, eles não suprem totalmente a demanda por água pluvial e necessitariam do auxílio de outra fonte para atende-la. Assim sendo, recomendados quando se deseja diminuir o volume do reservatório, diminuindo assim os gastos com a implantação do sistema.

Os métodos da simulação e prático australiano, por sua vez, atendem à demanda e não possuem um volume de valor tão elevado ao ponto de impedir a sua implantação. O motivo de esses métodos terem atingido valores de volume mais satisfatórios deve-se ao fato de serem métodos de tentativa e erro, ou seja, pode-se realizar a simulação dos volumes de reservatórios até que se chegue à eficiência desejada para o sistema, de acordo com os interesses do proprietário. Demonstrando assim que esses métodos chegariam ao volume considerado ideal para o objeto de estudo em questão.

\section{CONCLUSÃO}

Pode-se então concluir que os resultados de volumes de reservatório obtidos não indicaram nenhum padrão constante e provavelmente cada caso terá um método que melhor se adeque à sua situação. Sendo assim, apesar da existência de dispersões entre os volumes atingidos para o reservatório de armazenamento de água pluvial para os métodos propostos pela NBR 15527, a escolha do mais apropriado dar-se-á de acordo com os interesses finais de implantação de um sistema de aproveitamento de água pluvial e, também, em função da região de implantação. Por exemplo, em regiões com altos índices pluviométricos, deve-se optar por métodos que levem a volumes inferiores para o reservatório, o que o tornará mais economicamente viável. Enquanto em regiões com baixos índices o ideal seria utilizar métodos que superdimensionem o reservatório, para que a água captada nos períodos de chuva possa suprir a demanda nos 
períodos de estiagem. Dessa forma, fica claro que é de suma importância que seja conduzido um estudo comparativo antes da escolher um método de dimensionamento, para evitar implantação de projetos inadequados.

Isto posto, a determinação do método mais adequado de dimensionamento pode ser fundamentada na comparação dos volumes obtidos, em sua viabilidade em termos de área disponível no local onde será construído o reservatório e também no custo da construção do reservatório, o qual muitas vezes pode ser a parte mais onerosa do sistema. Aliado ao aspecto econômico, o aproveitamento de água de chuva para fins não potáveis, ao contribuir para a diminuição do consumo de água potável, resulta em ganho ambiental fundamental, visto que diminui a pressão sobre mananciais tornando possivel que esses recursos sejam direcionados aos consumos mais nobres, e por isso deve ser estimulado.

\section{REFERÊNCIAS BIBLIOGRÁFICAS}

AMORIM, S. V.; PEREIRA, D. J. A. Estudo Comparativo dos Métodos de Dimensionamento para Reservatórios Utilizados em Aproveitamento de Água Pluvial. Ambiente Construído, Porto Alegre, v. 8, n. 2, p. 53-66, 2008.

AGÊNCIA NACIONAL DE ÁGUAS - ANA. Conjuntura dos Recursos Hídricos do Brasil: Informe 2016. Brasília: ANA, 2016. $96 \mathrm{p}$.

AGÊNCIA NACIONAL DE ÁGUAS - ANA. Encarte Especial sobre a Crise Hídrica. Brasília: ANA, 2015. 31 p

ASSOCIAÇÃO BRASILEIRA DE NORMAS TÉCNICAS. NBR 15527: Água de chuva - Aproveitamento de coberturas em áreas urbanas para fins não potáveis. Rio de Janeiro, 2007.

CENTRO NACIONAL DE MONITORAMENTO E ALERTAS DE DESASTRES - CEMADEN. Mapa interativo da Rede Observacional para Monitoramento de Risco de Desastres Naturais do Cemaden. 2019. Disponível em: <http://www.cemaden.gov.br/mapainterativo/\#>.

Acesso em: 03 jan. 2019.
COHIM, E.; GARCIA, A.; KIPERSTOK, A. Captação e aproveitamento de água de chuva: dimensionamento de reservatórios. Simpósio De Recursos Hídricos Do Nordeste, 9, 2008, Salvador. Anais eletrônicos. Salvador: Associação Brasileira de Recursos Hídricos, 2008. p. 1-16. Disponível em: <http:\\teclim.ufba.br/ site/material_online/publicacoes/pub_art74.pdf>.

Acesso em: 28 set. 2019.

EMPRESA PAULISTA DE PLANEJAMENTO METROPOLITANO - EMPLASA. Sobre a RMSP. Disponível em:< https://www.emplasa.sp.gov.br/RMSP>. Acesso em: 27 set. 2019.

FERREIRA, M. I. P.; SILVA, J. A. F.; PINHEIRO, M. R. C. Recursos hídricos: água no mundo, no Brasil e no Estado do Rio de Janeiro. Boletim do Observatório Ambiental Alberto Ribeiro Lamego, Campos dos Goytacazes, v. 2, n. 2, p.29-36, 2008. Semestral. Disponível em: <http://www.essentiaeditora.iff.edu.br/index.php/bole tim/ article/viewFile/2177-4560.20080008/222>. Acesso em: 27 set. 2019.

INSTITUTO BRASILEIRO DE GEOGRAFIA E ESTATÍSTICA. Projeções da população: Brasil e unidades da federação: revisão 2018. 2. ed. Rio de Janeiro: IBGE, 2018.

MARINOSKI, Ana Kelly. Aproveitamento de água pluvial para fins não potáveis em instituição de ensino: estudo de caso em Florianópolis - SC. 2007. 107 f. TCC (Graduação) - Curso de Engenharia Civil, Universidade Federal de Santa Catarina, Florianópolis, 2007.

MAY, Simone. Estudo da viabilidade do aproveitamento de água da chuva para consumo não potável em edificações. 2004. 189 f. Dissertação (Mestrado) - Curso de Engenharia Civil, Universidade de São Paulo, São Paulo, 2004.

SPERANCETTA, D.; ALVES, J. V.; KRÜGER, C. M. Captação de águas pluviais para abastecimento residencial. da Vinci, Curitiba, v. 1, n. 1, p. 29-42, 2004. Disponível em:< http://www.up.edu.br/davinci/pdf02.pdf >. Acesso em: 27 set. 2019.

TUNDISI, J. G. Recursos Hídricos. Revista

Multiciência, Campinas, v. 1, p.48-62, out. 2003.

Semestral. Disponível em:

<http://www.multiciencia.unicamp.br/art03.htm>.

Acesso em: 27 set. 2019. 